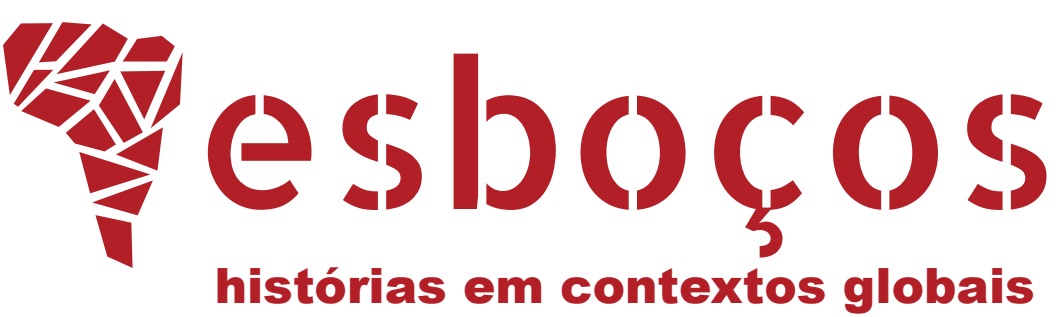

\title{
EXPLORING THE EMERGING DIGITAL SCENE IN ART HISTORY AND MUSEUM PRACTICE
}

Alexandros Teneketzis ${ }^{a}$ (1) https://orcid.org/0000-0002-9550-5858

E-mail: ateneketzis@aegean.gr

a University of the Aegean, Department of Cultural Technology and Communication, Mytilene, Greece

DOSSIÊ

História digital e global: novos horizontes para a investigação histórica 


\section{ABSTRACT}

This article addresses the current digital status in the fields of Museology and History of Art, both in Greece and internationally, in order to examine, record and analyse the extent of usage and the impact of digital tools. We will study the state-of-the-art in the fields of Museology and Art History, with a particular focus on examining the degree to which Greek institutions of culture and arts, as a case study in Europe, use state-of-the-art digital technologies (e.g., semantic technologies, augmented reality, and ubiquitous computing) for (a) storing, managing and documenting artworks together with all relevant knowledge/information; and (b) interpreting and presenting artworks to the public. We will also study and analyse the degree of interrelation between knowledge/information, and art and cultural heritage that is currently hosted in distinct cultural and art institutions around Greece, as well as between Greek institutions and relevant projects abroad. In this context, the issue at stake is the identity and the way Art History is exercised.

\section{KEYWORDS}

Digital Art History. Digital tools. Digital public space. 


\section{$\mathbf{T}$} he term Digital Art History is not new, of course, to the international bibliography. Already from the end of the past century, without any delay vis-a-vis the other practices of Digital Humanities, advocates of "analogue" Art History began to delve systematically into the then emerging computer-assisted processes and, soon after, into digital technology (ZWEIG, 2015, p. 40-41; BENTKOWSKA-KAFEL, 2015, p. 55-58). Admittedly, we live in a world where we communicate visually like never before, "inside oculacentric Western culture" (KARAMPA, 2018, p. 96). Art History possesses the tools and the experts capable of analysing and interpreting the visual culture and visual objects (KLINKE; SURKEMPER, 2016, p. 9), perhaps transforming in this way our discipline into visual studies, justifying the "so called visual turn of the 1990s" (GUIOKA, 2018, p. 12). At this point, however, Hans Belting observation that the debate on "whether art history, without losing its inherited particularity, should contribute towards this interdisciplinary discussion or not, thus leaving this field to others", is a pseudo dilemma. Belting is clearly in favour of dealing with anything that may be called a visual phenomenon (2018, p. 27).

As art historians, we have only marginally studied the impact of this evolution on our methodology and on the way we work, as well as on the essence of our discipline. Questions like the following will continue to be raised in the future: how - and in what respect - does the use of digital media influence our visual perception, our abilities to recognize the quality of artefacts or the interpretative process?

This raises yet another question: Are we moving closer to what Erwin Panofksy ironically called "rejection of the originals"? This issue will become even more pressing as the works of art are being transformed into images that people worship and increasingly use, unlike the physical objects themselves, while they can access them in thousands, beyond the natural human capabilities (KLINKE, 2019, p. 16-19). Like the discovery and use of photography within the Art History framework, this fact goes to confirm the view of Robert Koch, who claimed back in 1865 that the - now digital - "photographic picture of a microscopic object can under certain circumstances be more important than [the object] itself" (BREDEKAMP, 2003, p. 102).

In recent years, however, the state-of-the-art in artwork presentation and dissemination practices has shifted more and more from the public museum space to the private space of a teaching room or a living room, and back to the virtual public space through the Internet. At the same time, as a result of those changes, the study of Art History per se is being gradually transformed into the study of digital Art History. The study of artworks and their impact is now being re-initiated within the new, evolving digital scene.

Drawing on the above-mentioned landscape, this paper explores this new digital space evolving around Art History, Museology and other relevant fields of study. It will study, record and analyse the degree of interrelation between knowledge/information, on the one hand, and art and cultural heritage, on the other, as currently hosted in different cultural and art institutions around Greece, but also abroad. Furthermore, the study will examine the degree to which digital tools for artwork management and documentation adopted by Greek institutions are exploited in a way that actually enhances cultural content, but also knowledge discovery, thereby leading to a more complete and insightful presentation of exhibits. We will also study the current practices for digitally exhibiting and presenting artwork (online or in situ), in order to examine the degree to which these practices reflect the respective international state-of-the-art, with a focus on factors such as: the quality of user-machine interactions, that is, the quality and characteristics of the broader user experience achieved through technological means 
(e.g., the user experience of a visit to a virtual museum) compared with conventional practices; which additional services and functionalities are offered by those tools; the degree to which digital services and tools facilitate accessibility to cultural heritage and art content; and the methods for evaluating cultural user experience or for understanding and subsequently meeting the needs of cultural heritage users; among others.

\section{THE NEW MEDIA}

Digital media applications seem to be capable of collecting, linking and dynamically offering the huge amount of art context resulting from this fusion. Researchers, scientists, students and other stakeholders in the field will benefit from these platforms while accessing their valuable cultural heritage resources. Cultural institutions should also bear in mind that their visitors come from diverse backgrounds and want many different things when they visit cultural spaces. Their engagement with the exhibits or technologies also varies (KONSTANTAKIS; CARIDAKIS, 2020). It is of major importance to understand and try to adapt the technology, so as to be able to maximize meaningful experiences for the visitors. GLAM (Galleries, Libraries, Archives and Museums) institutions should balance the use of conventional ways of presenting exhibits to make them both more relevant and in step with technological changes, either by using more effective media, technology or interactive exhibits (OTHMAN, 2012). These new tools already transmute the way artworks are presented and, by extension, perceived and experienced, while transforming the exhibition space of artworks and shaping different interpretations on behalf of viewers, thus enriching and enhancing the visitors' experience in a personalised, immersive and engaging way.

It is also essential to integrate User Experience (UX) Design into Cultural Heritage $(\mathrm{CH})$. People visit museums to satisfy specific, often highly personal and/or sociocultural needs. GLAM staff should recognize that visitors arrive with their personal contexts, including agendas, interests, expectations, resources and identities. They use the GLAM setting, objects and experiences to build upon their personal contexts. To be effective, GLAM staff members need to learn how to support visitors' personal goals, agendas and outcomes, as well as those of the institution (KONSTANTAKIS; CARIDAKIS, 2020). The Cultural User eXperience (CUX) begins before the visit to the GLAM institution, includes experiences within the GLAM (interactions with staff and members, as well as with other visitors, exhibitions and materials) and continues long after the visitor leaves. Thus, GLAM staff should learn to better support the longterm learning and leisure trajectories of their visitors, tapping into their interests and agendas (KONSTANTAKIS; CARIDAKIS, 2020).

As modern trends indicate, visitors seek to be involved in extraordinary and unique experiences (KONSTANTAKIS; MICHALAKIS; ALIPRANTIS; MORAITOU; KALATHA; CARIDAKIS, 2018) especially those that enable them to experiment with new cultural creative services. Meanwhile, modern developments in the field of information and communication facilitate access to extended cultural databases, thus shaping new cultural products and "edutainment" methods. To meet high user expectations, designers tend towards bringing users into the design process of creating a new product or service, in an attempt to understand and then efficiently satisfy users' needs. Cultural institutions should, now, balance the use of traditional ways of presenting exhibits to make them at once more relevant and in step with technological changes, either by 
using more effective media, technology or interactive exhibits. Nonetheless, the main goal remains: understanding how academic communities and cultural industries view and measure Cultural User eXperience (CUX) is important in order to propose new methods and tools, and to disseminate best practices.

\section{A EUROPEAN CASE STUDY: THE GREEK EXAMPLE}

In Greece - as a case study in European context and following European practices and strategies under the European Union (EU) -, the implementation of digital media in the field of humanities has kept up with other disciplines, mainly through programs co-funded by the EU and the Greek State. ${ }^{1}$

Figure 1 - Online applications, National Historical Museum, Greece

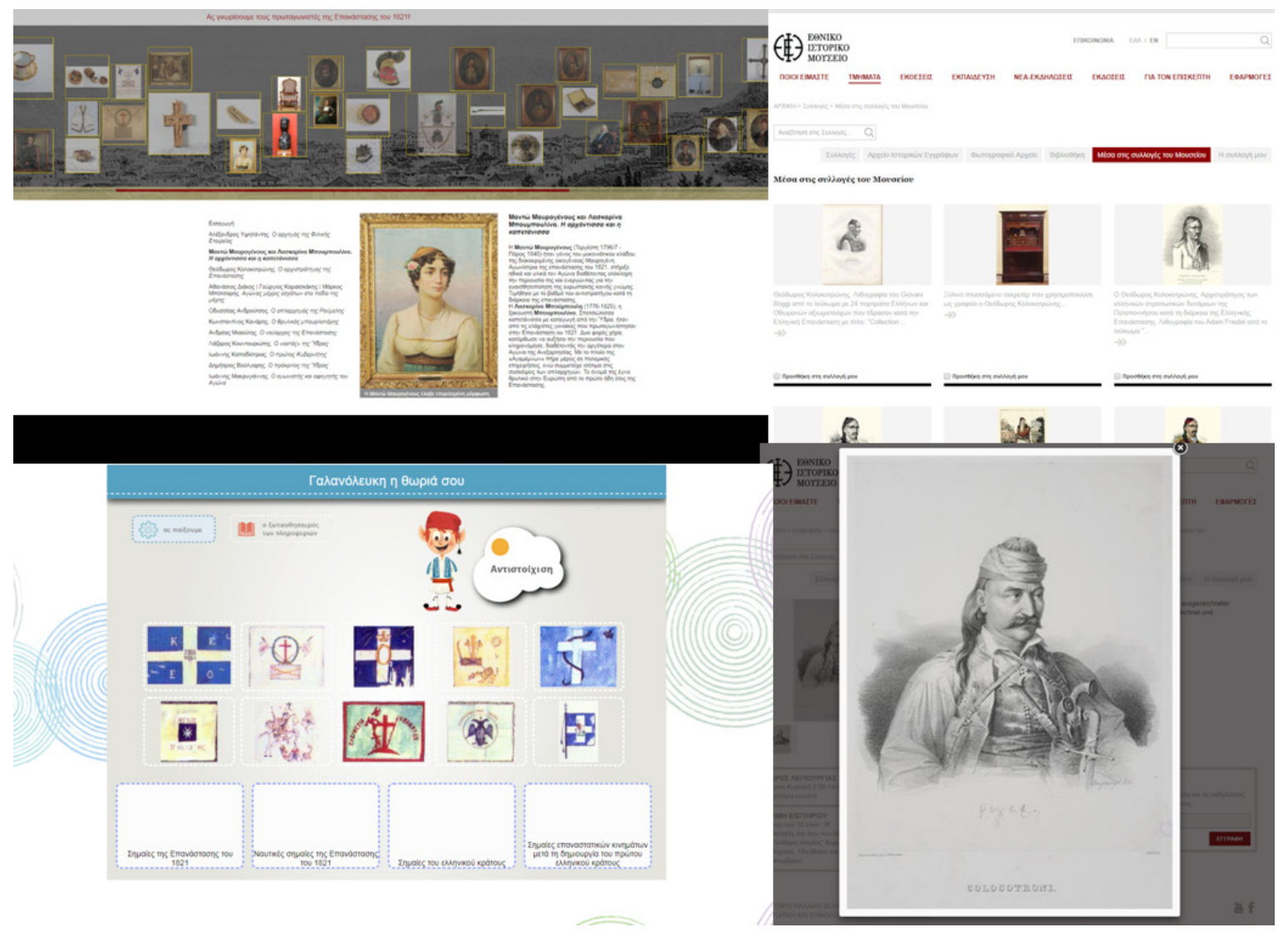

Source: http://www.nhmuseum.gr/en

Current examples, to mention but a few, are virtual museums such as the one set up by the National Gallery, ${ }^{2}$ 3D recreations, interactive timelines, mobile applications - which place objects of art in public spaces, like the ones implemented

\footnotetext{
${ }^{1}$ See the Greek National Strategic Reference Framework (NSRF) 2014-2020, Last modified May 21, 2019, http://www.digitalplan.gov.gr/portal/ and http://2007-2013.espa.gr/el/Pages/staticOPDigitalConvergence.aspx.

2 "National Gallery Athens, Digital Presentations", National Gallery Athens, Last modified May 21, 2019, http://www.nationalgallery.gr/en/digital-presentations.html.
} 
by the Zongolopoulos Foundation ${ }^{3}$-, cultural journeys, interactive exhibitions and educational programmes - such as the example of the National Historical Museum 4 - and virtual, digital museums like the one set up by the Byzantine and Christian Museum of Athens. ${ }^{5}$

Figure 2 - Byzantine and Christian Virtual Museum, Greece
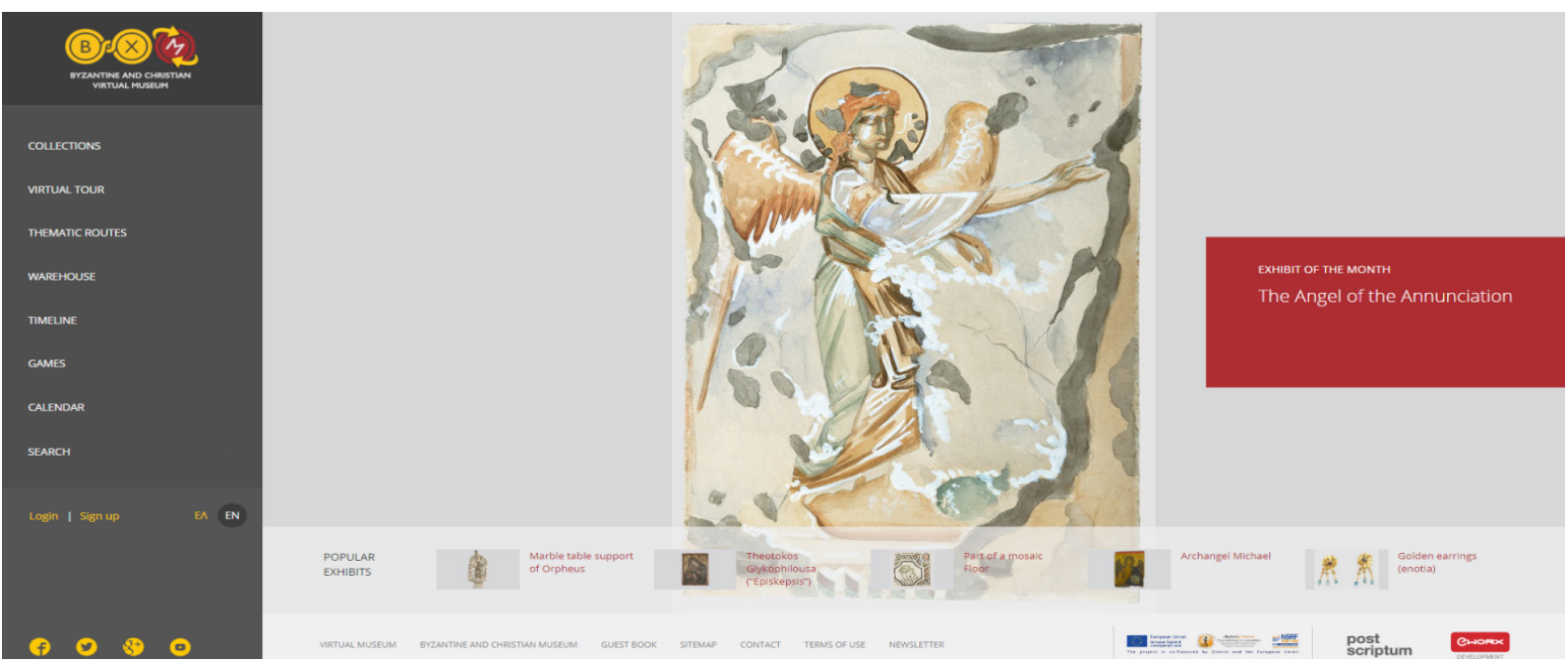

Source: http://www.ebyzantinemuseum.gr/?i=bxm.en.home

These projects attempt to link, for the first time, the country's cultural heritage with digital media, moving a step further from the simple digitization and documentation of objects of art. They also suggest new ways of showcasing, exhibiting and interpreting the selected material. For the first time, the digital visitor, now called a "user", may "visit" a museum from the comfort of his or her home, virtually entering a new state, living an alternative experience and reality, and breaking away from his or her circumstances. This trend seems to be a constant quest today, as shown by the success of virtual games and virtual reality (RAE; EDWARDS, 2016). However, these attempts still stay away from implementing digital tools such as semantic technologies, augmented reality or ubiquitous computing to interpret the cultural content without a human intervention, and they take research results computationally.

\footnotetext{
3 "Zongolopoulos Foundation", Zongolopoulos Foundation, Last modified May 21, 2019, http://www. zongolopoulos.gr/en.

4 "National Historical Museum", National Historical Museum, Last modified May 21, 2019, http://www. nhmuseum.gr/en.

5 "ebyzantinemuseum", e-Byzantine and Christian Museum of Athens, Last modified May 21, 2019, http://www.ebyzantinemuseum.gr/?i=bxm.en.home
} 
Figure 3 - Online applications, Zongolopoulos Foundation, Greece

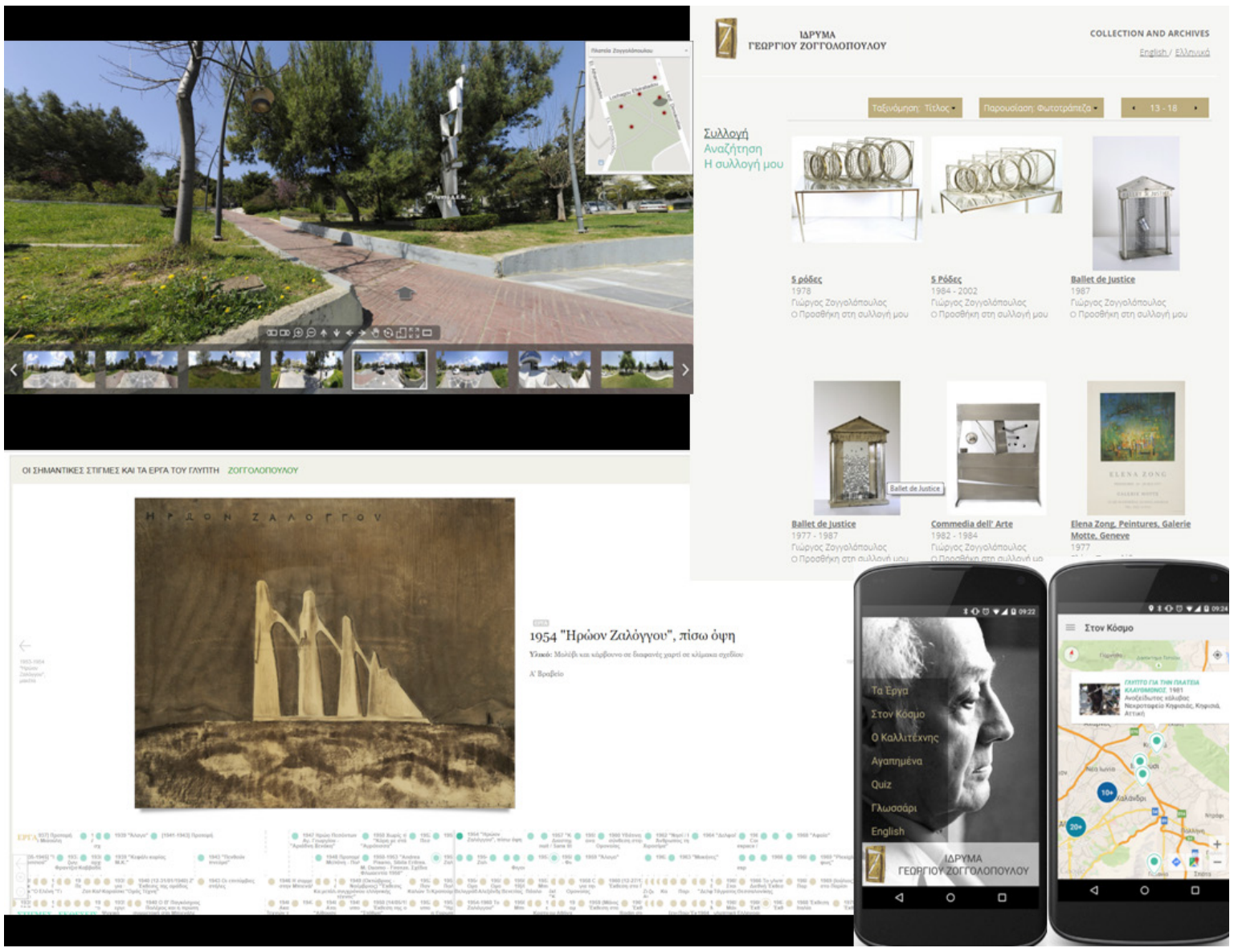

Source: http://www.zongolopoulos.gr/

At the same time, according to the demands of a digital globalized market, these projects will push culture forward into the digital era, connecting it to the tourism sector and attracting potential digital and physical visitors (TENEKETZIS; PIERROY; KARATZA, 2018). Amidst this chaotic flow of information, the aforementioned efforts, as well as similar ones, may serve as legitimate and easily accessible sources of information, facilitating the operation of their organizations, as well as the documentation of collections and the exchange of scientific knowledge. Even more important, the digital outcome can be part of other European projects, such as Europeana, enriching in this way international digital projects through the use of an application programming interface (API).

The website searchculture.gr, ${ }^{6}$ which carries the explanatory tagline "The Greek cultural heritage in the public digital sphere", is the culmination of this effort and an indicative example of how a cultural reserve can be exhibited using new technologies. Having said that, this effort has certainly enhanced proper digital curation, public access and the openness of cultural information. Yet, it is still a static presentation, which ignores the interpretative process, the comparative study of digital items or any other classification beyond a strict chronological one, which would otherwise have placed broader phenomena into a historical context and would

\footnotetext{
6 "Greek Cultural Heritage", Greek Cultural Heritage in the digital public space, Last modified May 21, 2019, https://www.searchculture.gr/aggregator/portal/?language=en.
} 
have explained clusters or historical "coincidences", or even the linkage with PanEuropean movements or phenomena. What it does promote is a digitized version of the history of art and of archaeology, instead of a digital one. It seems to promote to the Greek, as well as the international public sphere - namely the "public digital space" - the uninterrupted continuation of our civilization from 3,000 BCE to the present, simply through the availability of digital content, as shown by its timeline, which is the only application available on the platform.

Figure 4 - Online applications, National Documentation Centre, Greece

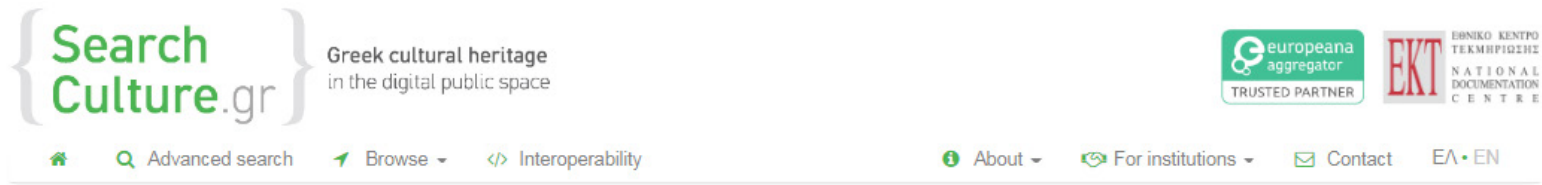

\begin{tabular}{|l|l|l|}
\hline Enter word or phrase & In all fields & $\checkmark$ \\
\hline More search options & Search & \\
\hline
\end{tabular}

\section{Explore 523,754 items from 63 institutions}

SearchCulture gr is the Greek Aggregator for Cultural Heritage Content, a cultural digital space

developed by EKT in collaboration with Digital Convergence. It aggregates Greek Digital Cultural Content produced by institutions through public funding

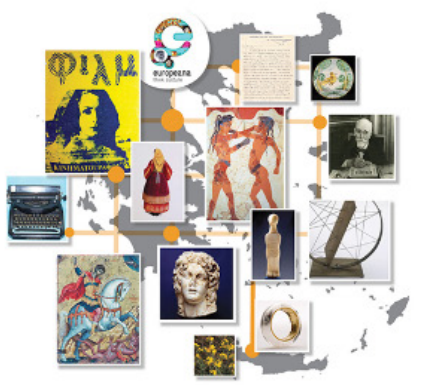

timeline | navigate to the content through all historical periods.

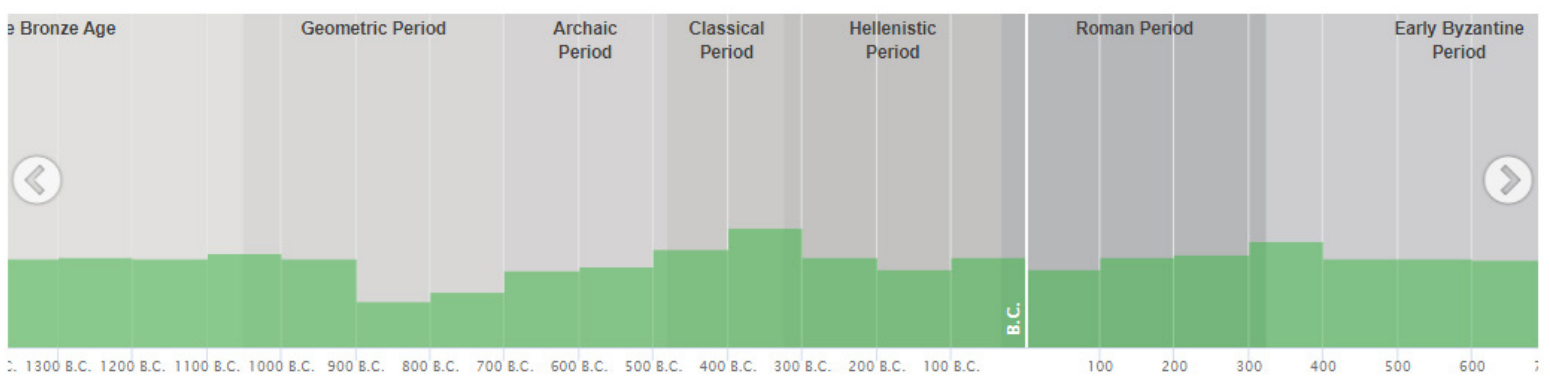

Source: http://www.searchculture.gr/aggregator/portal/?language=en

It seems that during the past decade, there has been a change in the museum's interpretation and visualization of cultural heritage. Attention is focused on the Greek past, but museums are currently confronted with changing public expectations regarding how to use and offer this content. By means of digital technologies, objects in collections and exhibitions still remain exclusively accessible on-site or stored in collection databases as digital reproductions. In this regard, most museums put a considerable amount of effort in the attempt to display their content and their central narrative through their websites. Furthermore, they develop a multichannel communication strategy that would shed light on the 
importance of technological aid in making cultural heritage content more easily and efficiently accessible to the public. However, as we saw above, in most cases, they only partially succeed - in terms of language barriers, technology limitations or limited access to content. It seems that institutions do not yet take advantage of the new media or web.4, as they stay on a digitized and simply informative level, away from digital and interactive solutions with multiple interpretations that computational innovations offer.

\section{INTERNATIONAL PRACTICES}

However, digital applications and software like Google Art and Culture, Europeana, Van Gogh Alive, $360^{\circ}$ video and apps like Shazam for Art, as well as morphing technologies, do change the way we view works of art, i.e., the way we perceive and use them, possibly also changing the identity of the viewer, who used to be a physical visitor to a museum and now becomes the visitor of a virtual space, eventually ending up as a user and consumer of a technological product. Consequently, the viewing area of objects is in constant transformation. A different receiving area is evolving, as we leave the public space of the museum for a private residential space or a classroom, which at the same time becomes again public, infinite and global, thanks to the Internet. "Globalization and the cutting-edge tools afforded by new technologies are doing away with boundaries or any obstacles (time and space related) as far as the dissemination and circulation of artistic and cultural works and goods are concerned, as well as the development of culture in general" (AGIOVLASITIS; TSIAVOS, 2018, p. 24).

For example, through the Thesswiki project platform, ${ }^{7}$ using Wikipedia as a vehicle, the tangible and intangible cultural heritage of Thessaloniki is uploaded to the global internet encyclopaedia and then, using QR codes, its information is redirected to the physical public space for further consumption. The link between physical and digital spaces acquires a meaning of its own as the interaction takes place regardless of one' setting. Each user is always free to choose how to access, or, rather, how to use, the available data.

\footnotetext{
7 “Thesswiki Project”, Thesswiki, Last modified May 21, 2019, http://thesswiki.com/en/.
} 
Figure 5 - The Thesswiki online crowdsourcing platform

$Q \equiv$
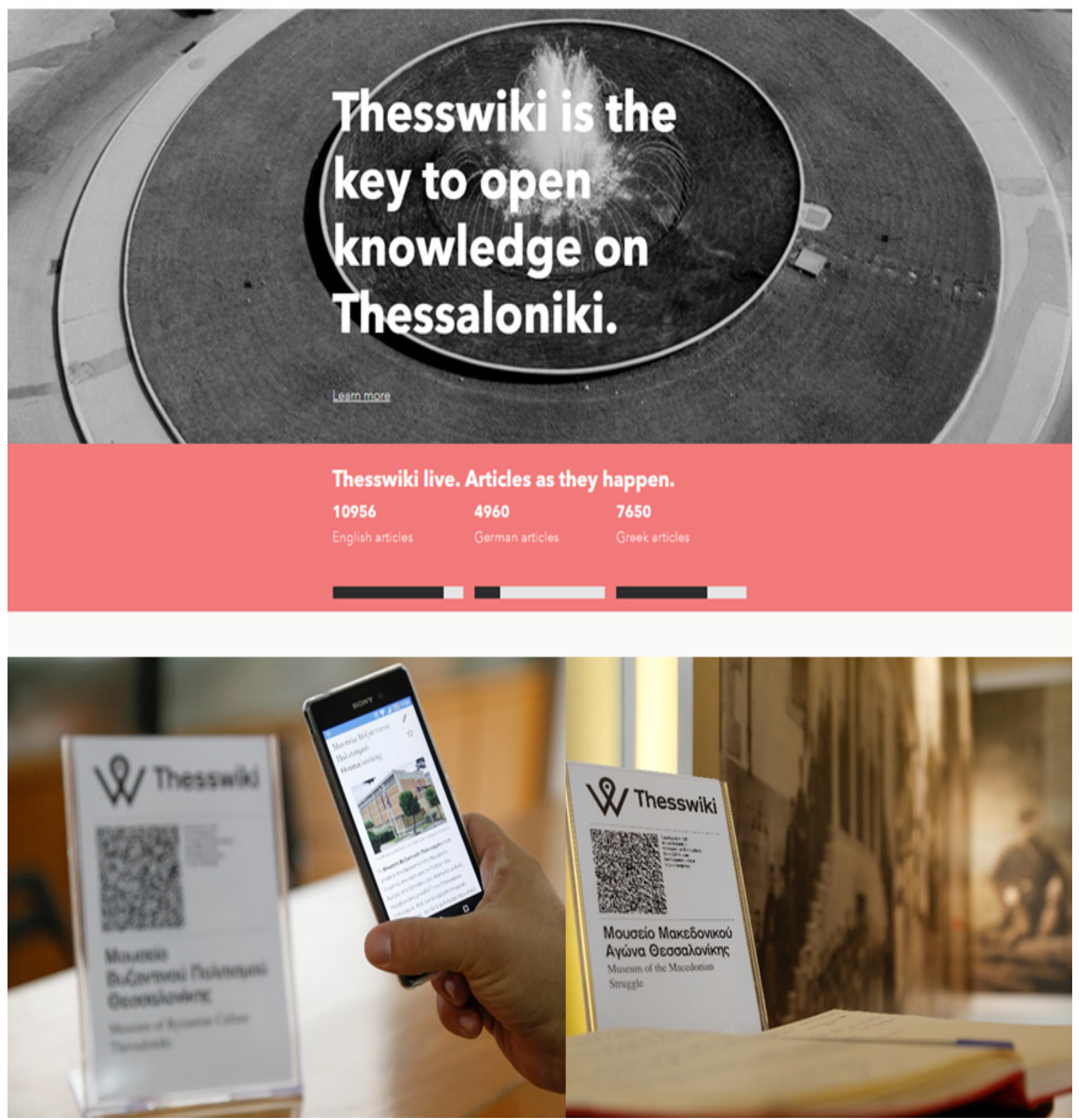

Source: http://thesswiki.com/en/

However, could it be that the user's role is simply reduced to that of an information consumer, since he or she remains deprived of any direct contact with the works of art or monuments themselves? Could it be that instead of enriching our interpretative acquis with a view to a better and fuller understanding of the works of art, even the digital situation does not help us avoid an alternative reality as described above? As Malraux (2007, p. 211) stated about conventional museums, the "works of art are being revived inside our own world of art, not their own". Attempting to interpret the relationship between image and original work of art, Horst Bredekamp (2003, p. 103) concludes that this relationship is "the basic conflict in art history: that it depends 
largely on the autopsy of the original but that it questions it also through the lens of photographic-founded knowledge".

Figure 6 - Online applications, Bruegel Unseen Masterpieces, Google Arts and Culture

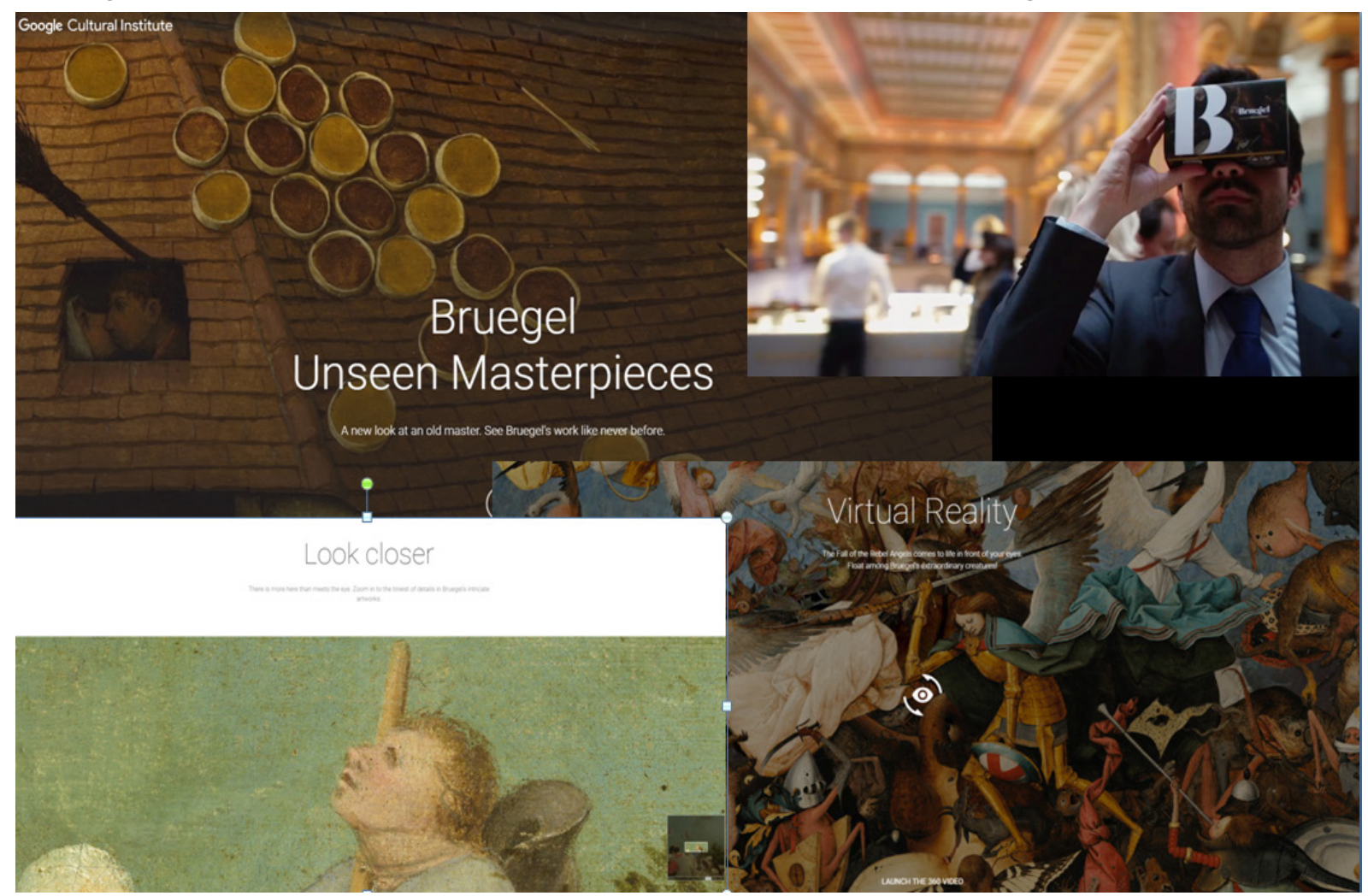

Source: http://www.google.com/culturalinstitute/bruegel/

Still, there is an effort, with the aid of technology, to increase the number of dimensions of the traditional photographic capturing of works of art to at least three, considering the way people perceive them. This is the case of a project implemented by Google in collaboration with the Royal Museums of Fine Arts of Brussels, focusing on the art of Bruegel, ${ }^{8}$ as well as another case study concerning Picasso's Guernica ${ }^{9}$ at the Reina Sofia museum in Madrid, where 3D re-creations and high definition photographs are complemented by archival documents. Thus, the painting has been given an unprecedented wealth of metadata, helping us reconsider the Spanish artist' subversive work. Along with the documentation metadata, we have therefore the capacity to study every aspect and dimension of the artwork and raise new questions regarding its era and its creative process, thus placing digital media - which are much more than mere reproductions and images - in the service of Art History.

\footnotetext{
8 "Bruegel, Unseen Masterpieces", Google Arts and Culture, Last modified May 21, 2019, https://www. google.com/culturalinstitute/bruegel/.

9 "Rethinking Guernica", Guernica - Museo Reina Sofia, Last modified May 21, 2019, https://guernica. museoreinasofia.es/en.
} 
Figure 7 - Online applications, Rethinking Guernica

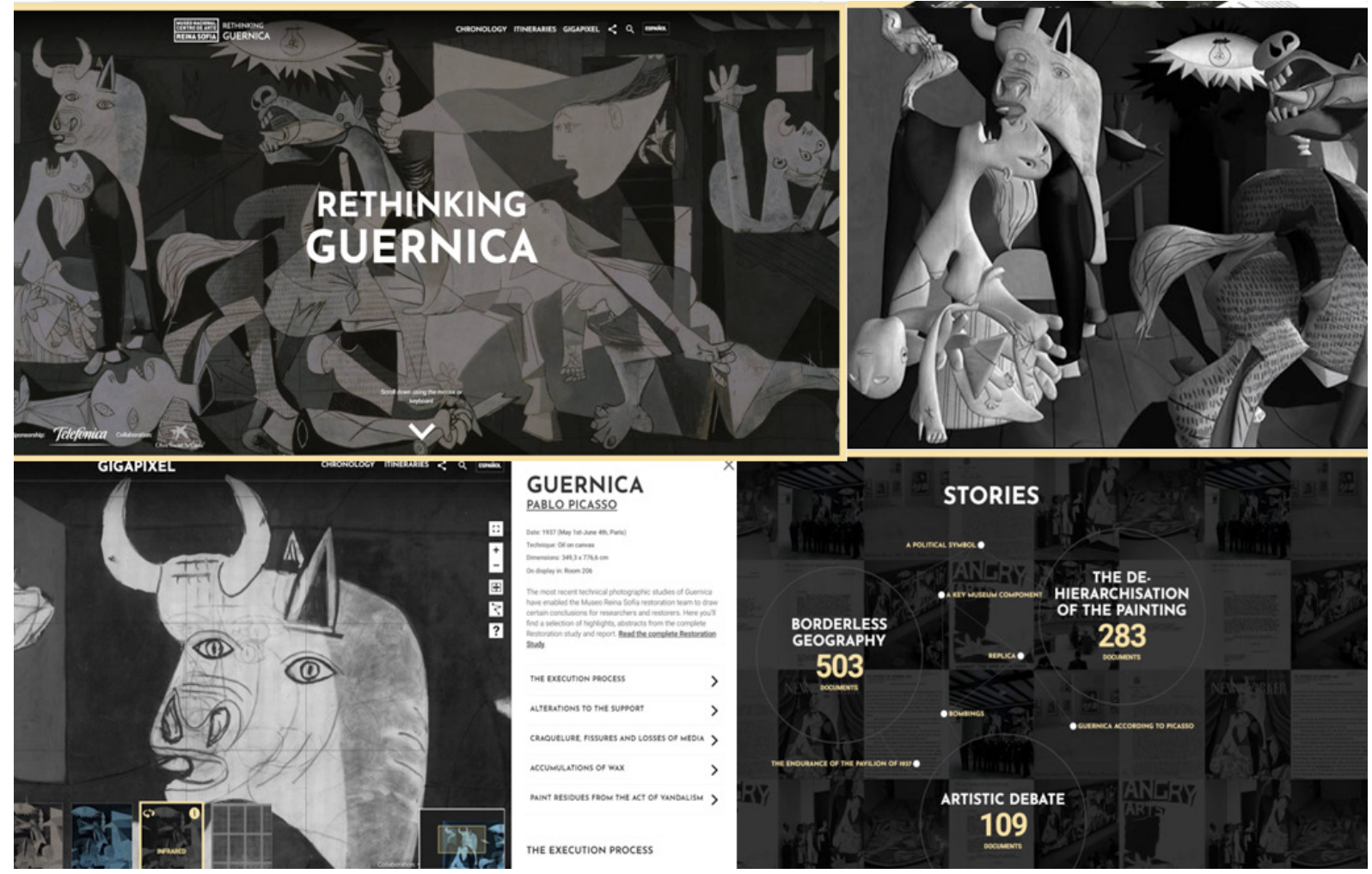

Source: http://guernica.museoreinasofia.es/en

Nevertheless, we should always bear in mind that by using the digital document as our only source, in reality we are dealing with numbers and algorithms in a computerized mathematical context, connecting pixels and gigapixels in what is now called Big Data (KLINKE, 2019, p. 17). We are not even standing in front of an image but rather, a set of data, a multidimensional autonomous space of virtual and digital reality, which, in turn, becomes a point, a dot inside another multidimensional space made up of data. This space is now defined, not according to Art History-criteria, but, instead, according to statistical and computing outcomes, thus casting doubts on the very nature of the prototype and its material existence - a prototype that is threatened to lose its historical nature and the character of an intellectual ideological product. As Guioka (2018, p. 12) claims, it is the science of images the one that may "depict in real time, with technical methods, what the human vision cannot capture due to size, distance, composition, or position".

Hence, it seems that - after their initial crafting - artistic creations change for a second time their identity and character, since after their first "exile" and isolation in a physical museum or gallery, where they have lost their utility and function to become simply "objects of Art" (MARLAUX, 2007, p. 36), once again, in today's digital world, they become digital data, that is, an "image" available for infinite processing and use. Speaking of the anthropology of the image, Belting (2018, p. 27) correctly remarks "that visual production and visual experience, in general, often tend to be confused with image, specifically. However, in my view, the image must be recognized as a symbolic entity (as well as an object of selection and memory) and distinguished from the constant flow of our visual environment". 
Granted: until recently, we could only compare a few phenomena among themselves - just a handful of works of art, out of those produced at the same time, in the same place. Our conclusions, therefore, would have been based on a finite volume of data, depending on what any given researcher would be able to collect and process at the time. Today, there are no limits to the size and volume of quantitative research, although there is a limitation regarding qualitative comparison. At this point, Art Historians must keep up with developments and raise historical, rather than datacentric criteria, pushing comparison beyond findings of the type, 'the yellow of cadmium discovered in 1818 was popular among impressionists, and we encounter this in $X$ number of works'. As Google and Europeana soon realized, the millions of documents in their databases needed to be presented in a specific manner and in specific quantities in order to be comprehended by the people. The offered material/product should be attractive to the users-viewers. Therefore, thematic entities and virtual exhibitions have been created, naturally taking into account the Art History principles, otherwise the results would have been meaningless and the artworks would have merely been pixels on a digital image. ${ }^{10}$

Still, certain limitations do exist. Space will always be confined to the twodimensional surface of the computer, tablet or mobile phone, no matter how much the new applications create the illusion of real space, as shown in the "Guglemann Galaxy, Schweizer Kleinmeister: An Unexpected Journey" project (BERNHARD, 2016). The direct contact with the objects, or the knowledge of true dimensions, materials and colours, unfortunately cannot be substituted by the new capabilities offering mass access and comparative analysis of the objects, despite the fact that the artworks are accompanied by their full documentation. There will always be doubts regarding the correct colour reproduction on the computer screen, despite the new media allowing us to see details that would have otherwise been impossible to see with the naked eye; despite being able to reconstruct virtual monuments, painting compositions and historical exhibitions of the past; and despite the new media's contribution to education. Guioka (2018, p. 9) concludes,

the consequences for the founding myths of this science are critical: it is now becoming clear that the images which seem to recreate nature in the most convincing way (hence producing the best scientific outcomes for the scientists) are exactly those which have been tampered with the most, using specific technological interventions.

At this point an old debate within Art History circles resurfaces, regarding the value and the differences between the reflection and the image, between what is readily visible and its visual and conceivable construction or reconstruction (BELTING, 2018, p. 27).

\footnotetext{
10 See "Europeana collections", Europeana, Last modified May 21, 2019, https://www.europeana.eu/ portal/el, and "Google Arts and Culture", Google Arts and Culture, Last modified May 21, 2019, https:// artsandculture.google.com/.
} 
Figure 8 - Digital exhibition, Van Gogh Alive

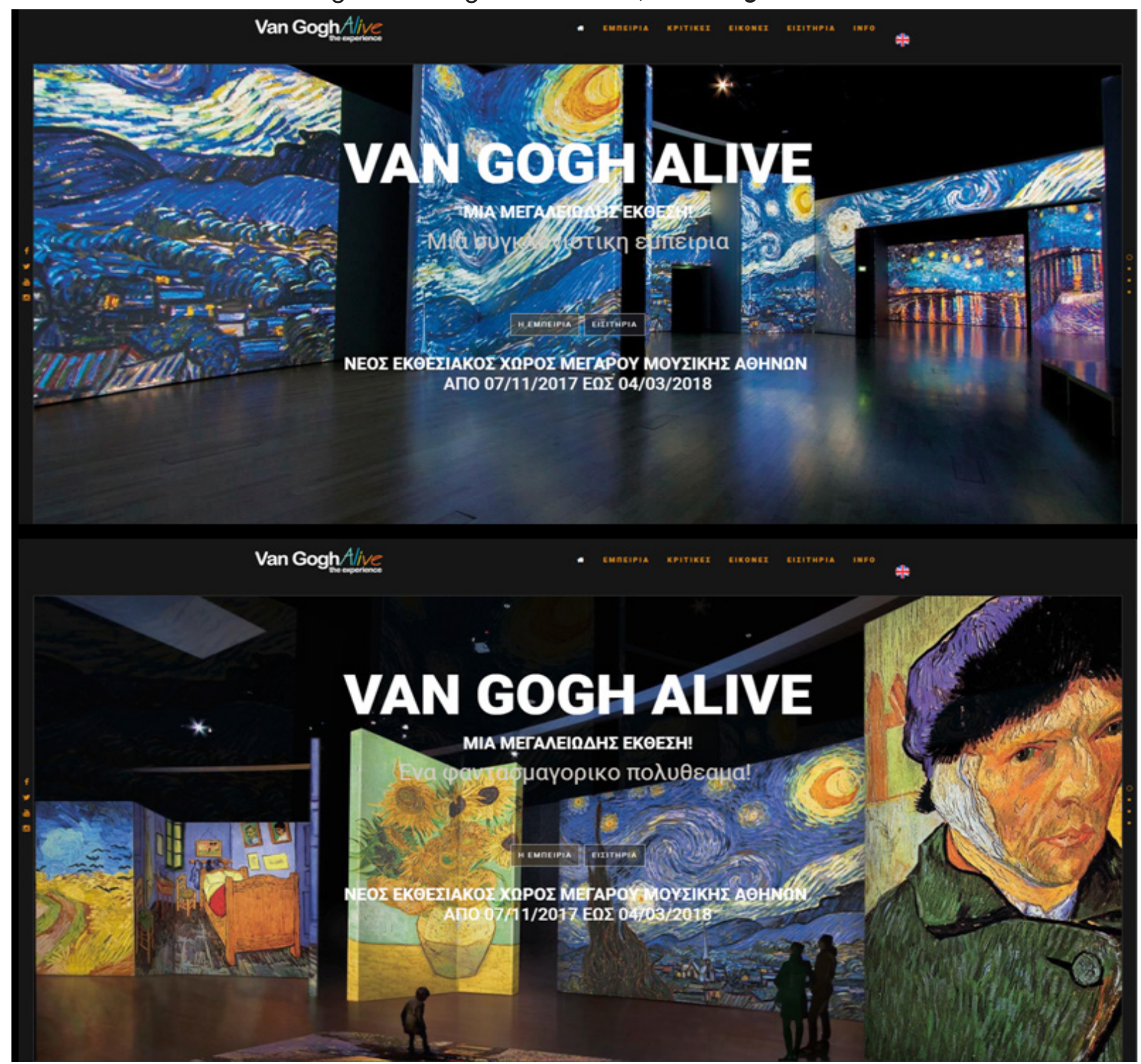

Source: http://www.megaron.gr/default.asp?pid=5\&la=1\&evlD=3837

Nevertheless, we should still be aiming to analyse an artwork's metadata as well, instead of merely looking at the technical characteristics of the images before us. Our aim is for Digital - rather than simply Digitized - Art History, in order to surpass the obstacle of the factual analysis of images, and for new media to facilitate the artistic and ideological dimension of works of "high" or "low" art, just like photography and slides once did, opening up new research possibilities in the cases of Warburg and Panofsky. Otherwise, the next stage would involve the use of images of works of art solely for entertainment purposes, such as in the case of exhibit Van Gogh Alive. ${ }^{11}$ Using techniques that promote immersive and experiential participation, its visitors simply become part of a static interaction, of an illusion of total approach of the works of art - which, however, have lost their material existence, their analogies, their true

11 "Van Gogh Alive”, Van Gogh Alive, Last modified May 21, 2019, https://www.vangoghalive.gr/indexen.html. 
dimensions or the feeling of a tangible object in space, and ceased to be creations made with means and materials belonging to a specific era.

Contrary to that, in this "breathtaking experience", or "fantastic spectacle", as the tagline of this "grand exhibition" states, the viewer is distracted from the historical context and is immersed into a "powerful, pulsating symphony of light, colour and sound", a "majestic experience, fun and at the same time educating", "a visually spectacular experience", "a full dive into breathtaking images", as we read in the exhibition's brochure text. The works of art are no longer documents of a society's culture and ideology but simply become part of an interaction in synchrony. This, however, deprives the user of the ability to think and comprehend the works of art themselves, and their methods of production with regard to similar artistic phenomena of the same era, practically forming a relation in which "we tend to imagine as present something which in reality has materialized long ago and we apply the same capability to the external images that we fabricate" (BELTING, 2018, p. 40). This nowadays allows the curators of the exhibition/show to attribute any interpretation to the psychological standing of the creator's character, promoting individuality and subjectivity vis-à-vis any sense of collective and historical integration. Van Gogh's painting style - which, in any case, cannot be assessed by the visitor - is simply being interpreted as the reflection of his troubled and psychologically unstable personality, which has nothing to do with the post impressionism or expressionism of the troubled era at the turn of the $20^{\text {th }}$ century. His involvement with landscape painting and open spaces is attributed by the curators to the "artist's inner void", and the "Wheatfield with Crows" image, to his "troubled mental state", implying that the impending darkness, or even death, was a reflection of his great distress and loneliness.

\section{NEW CHALLENGES IN ART HISTORY}

Notwithstanding the above-mentioned observations, in reality, the millions of objects and items of this new digital environment, as well as their artistic and theoretical work, are being ignored to a great extent. Most of the information and research remain scattered on the internet or in scientific books and articles, undocumented and invisible to the scientific community - in Greece, at least. Consequently, the direct or indirect interaction of the new digital media with the discipline of Art History remains invisible and vague. Yet, as "techniques of visualizations and reproduction, they are influencing the production of knowledge and define the structure of perception itself" (GUIOKA, 2018, p. 10), transforming it - or not - into a History of Images. The explosive development of new technologies in all areas of human computer interaction is obviously resulting in a change in the way in which the protection and interpretation of cultural heritage is perceived and managed today. Cultural organizations, following the developments of the era and making use of the new possibilities offered to them, have almost completely revised their way of functioning, seeking to integrate new technologies into their individual actions and the production of their goods in order to preserve their cultural achievements, but also to ensure their viability through the fulfilment of their role (KONSTANTAKIS; CARIDAKIS, 2019).

In this discussion, we should certainly take into account developments in the field of humanities and historical studies in general, where we may observe a considerable expansion of the subject and the various fields dealing with the assessment of the 
past. The examination of a contemporary historical culture that has been adapted to the history of art is of value, to the extent that we examine the future and value of works of art within the context of a newly emerged digital reality. This reality continues to be a priority for the European Union - see, in this respect, its new directions for the period ending in 2020 as a new digital strategy for culture in terms of 'smart specialization' on the part of European States, laying down digital readiness indicators that each country must achieve. A case in point is the institution of Digital Champion, which oversees the completion of the transition to the digital era. ${ }^{12}$

For the first time, with the Work Plan for Culture (2015-2018), the EU Council has adopted a decision, according to which, cultural heritage is a strategic resource for a sustainable Europe. In this framework, it addresses the main challenges facing the organizations managing cultural heritage and meets the needs of the small-medium sized enterprises and creative sector on a national and European level, within the context of creating a global digital cultural market (AGIOVLASITIS; TSIAVOS, 2018, p. 25).

Furthermore, a new parameter in this equation must be taken into account; the Art historian needs to develop a new skill, because in addition to being a scholar of visual products, she/he now acts as a producer. A digital museum receives something that is authentic, based on objects found in the physical museum, and turns it into something authentic based on information, in digital conditions. We must, therefore, also take into account a new development, according to which the so-called "information" is what constitutes the main force of a cultural organization, rather than the cultural "treasures" in its possession. This forces us to assume new positions as information/informatics scientists.

In such an environment, however, from a historian of visual arts of the past, the art historian now turns into someone who studies images; into a student of the contemporary historical culture, or as Mitsos Bilalis (2015, p. 9-10) put it, of the contemporary understanding and interpretation of historical phenomena - in our case, the works of art. Could it be that Art History is becoming a history of images, that is, a process of merely examining reproductions, as Malraux (2007, p. 26) had, once again, prophetically described? Or, rather, are we transitioning towards a science of images which "deals with tangible images and researches aspects like their origin, their psychological impact or the particularities of the medium as well as the content and their social meaning" (GUIOKA, 2018, p. 11), a Bildwissenschaft as an assessment of history of culture and civilization in general? Let us not forget that "wars" on history are very often waged as "wars" on image, that is, as public and digital wars (BILALIS, 2015, p. 8). Nowadays, many of these wars are virtually taking place on the screen of a computer or a game console, thus prompting greater involvement and historical conscience through virtual immersion than any other historical approach (STOURAITIS, 2018).

\footnotetext{
${ }^{12}$ See http://eige.europa.eu/resources/digital_agenda_en.pdf, https://ec.europa.eu/digital-single-market/ en and https://ec.europa.eu/digital-single-market/en/europe-2020-strategy. Date accessed: 21 May, 2019.
} 


\section{CONCLUSION}

To sum up, museums serve multiple functions in society, including safeguarding and providing public access to cultural content. Currently, museums are confronted with changing public expectations as to how to use and offer this content. By means of digital technologies, objects in collections and exhibitions are no longer exclusively accessible on-site or stored in collection databases as digital reproductions; now, they can be openly distributed and made widely accessible via the Internet. In this regard, both political and social actors, such as the EU and the Open Knowledge Foundation, have called on museums to make their digital collections openly available, though initiatives such as "OpenGLAM". Museums' staff teams have been increasingly expected to respond to these calls. Therefore, with the rapid development of modern information technology and network popularization, the digital transformation of cultural data management has become an inevitable trend. Digital information technology can achieve effective storage, rescue protection and utilization. Digital technology in cultural heritage provides technical services and guarantees for cultural research (ESTERMANN, 2016).

In this context, all questions regarding previous decades, when even the very existence of Digital Art History was in doubt, have now changed dramatically. The focus has shifted to a great extend from a simple data comparison based on computer processing power (colour, shape, pattern) to a direction focusing on identity and the way our discipline is practiced. In the era of "image worshiping" that we live in, it is not enough for someone to appear to be just an art historian, or even an image historian. Within the framework of imagining science, one must also be a historian, a public historian, a digital historian and a digital art historian; one must possess computer and communication skills, and so on, and so forth...

Could it be that from the era of over-specialization we are now entering an over-information phase, which, however, prohibits a deeper approach of historical events and phenomena - i.e., the works of art themselves? Alternatively, should we just tame and adjust the new means, as well as the ones about to appear in the future, as far as our own methodological and interpretative tools are concerned? This has happened in the past with the use of gravure and early photography, as well as with the advent of projector and slides in university halls one century ago (MARLAUX, 2007, p. 26). In this internal discussion, we should certainly take into account developments in the field of humanities and historical sciences in general, where we may observe a considerable expansion in the subject and the various fields dealing with the assessment of the past. The examination of a contemporary historical culture that has been adapted to the history of art is of value, to the extent that we examine the future and value of works of art within the context of a newly emerged digital reality. It seems, once again, that Malraux (2007, p. 26) correctly predicted, we "have more important works in our disposal than even the biggest museum could ever have". Still, it is up to the art historians to decide which epistemological direction they are going to choose. The historical approach of visual phenomena and works of art seems nowadays to be crucially at stake. 


\section{REFERENCES}

AYIOVLASITIS, Iraklis; TSIAVOS, Prodromos et.al. (ed.). Digital Strategy in

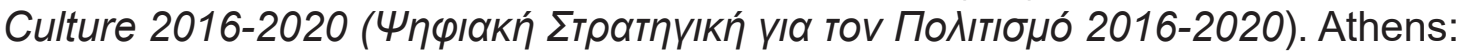
PostScriptum, 2018. Available at http://www.postscriptum.gr/media/1979/ digitalstrategy_final.pdf.

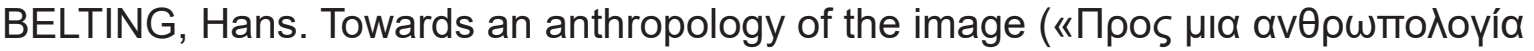

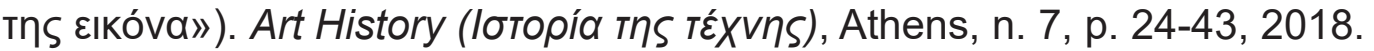

BENTKOWSKA-KAFEL, Anna. Debating Digital Art History. International Journal for Digital Art History, Munich, n. 1, p. 50-65, Oct. 2015. Available at: http://dah-journal. org/issue_01.html. Date of Access: May 21, 2019.

BERNHARD, Mathias. Gugelmann Galaxy. An Unexpected Journey through a collection of Schweizer Kleinmeister. International Journal for Digital Art History, Munich, n. 2, p. 95-116, Oct. 2016. Available at: http://dah-journal.org/issue_02.html. Date of Access: May 21, 2019.

BILALIS, Mitsos. The Past in the Web. Image, Technology and Historical Culture in

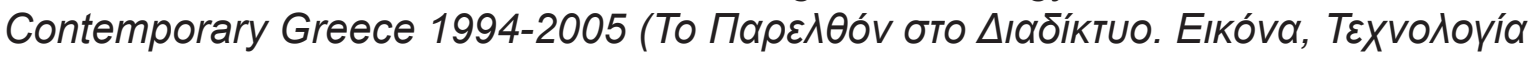

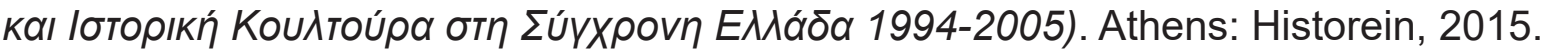
Available at: http://www.historeinonline.org. Date of Access: May 21, 2019.

BREDEKAMP, Horst. A Neglected Tradition? Art History as Bildwissenschaft. Critical Inquiry, Chicago, v. 29, n. 3, p. 418-428, 2003. Available at: https://philpapers.org/rec/ BREANT-4. Date of Access: May 21, 2019.

ESTERMANN, Beat. OpenGLAM. Der neue Trend unter den Gedächtnisinstitutionen. Bibliotheksdienst, Berlin, v. 50, n. 1, p. 137-140, 2016.

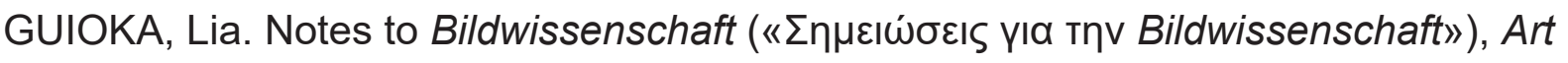

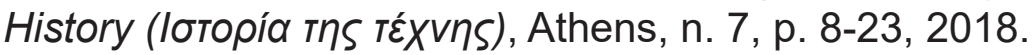

KARAMPA, Elpida. The Museum as a battleground and other stories about the image

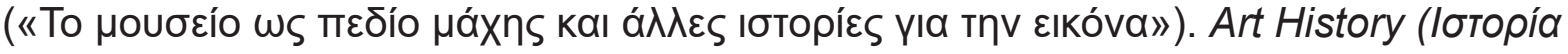

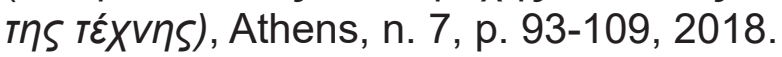

KLINKE, Harald. Big Image Data within the Big Picture of Art History. International Journal for Digital Art History Munich, n. 2, p. 15-40, Oct. 2016. Available at: http:// dah-journal.org/issue_02.html. Date of Access: May 21, 2019.

KLINKE, Harald; SURKEMPER, Liska. Big Image Data as new research opportunity in Art History. International Journal for Digital Art History, Munich, n. 2, p. 8-14, Oct. 2016. Available at: http://dah-journal.org/issue_02.html. Date of Access: May 21, 2019. 
KONSTANTAKIS, Markos; CARIDAKIS, George. Adding Culture to UX: UX Research Methodologies and Applications in Cultural Heritage. ACM J. Comput. Cult. Herit., v. 13, n. 1, Article 4, February 2020.

KONSTANTAKIS, Markos; MICHALAKIS, Konstantinos; ALIPRANTIS, John; MORAITOU, Themis; KALATHA, Eirini; CARIDAKIS, George. A Methodology for Optimised Cultural User peRsonas Experience - CURE Architecture in Human Computer Interaction Conference, Proceedings of the 32nd International BCS Human Computer Interaction Conference (HCl): July 2018.

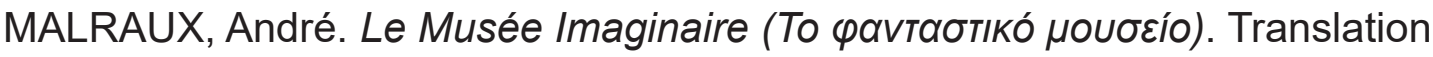
Eliades Nikos. Athens: Plethron, 2007 (1 ${ }^{\text {st }}$ French edition 1965).

OTHMAN, Mohd Kamal K. Measuring visitor's experience with mobile guide technology in cultural spaces. 2012. 343 p. Phd Thesis (Doctor of Philosophy) Computer Science Department, University of York, York, 2012.

RAE, Juno; EDWARDS, Lizzie. Virtual reality at the British Museum: What is the value of virtual reality environments for learning by children and young people, schools, and families?. Museums and the Web, Silver Spring, 2016. Available at: https://mw2016.museumsandtheweb.com/paper/virtual-reality-at-the-british-museumwhat-is-the-value-of-virtual-reality-environments-for-learning-by-children-and-youngpeople-schools-and-families/. Date of Access: May 21, 2019.

STOURAITIS, Elias. Playing the Second World War: Comments on the war in

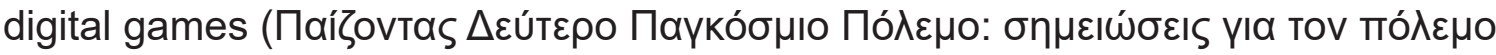

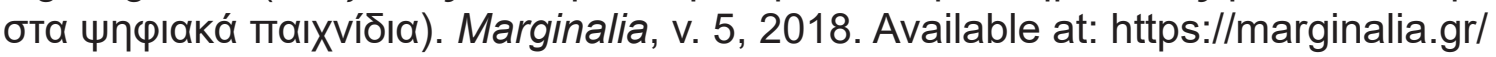
arthro/paizontas-deytero-pagkosmio-polemo-simeioseis-gia-ton-polemo-sta-psifiakapaichnidia/. Date of Access: May 21, 2019.

TENEKETZIS, Alexandros; PIERROU, Vasia; KARATZA, Mina (edit). Digital Sustainability: New Perspectives for Museums and Cultural Organizations,

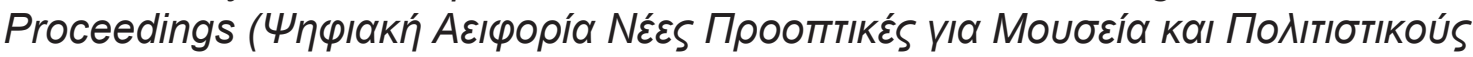

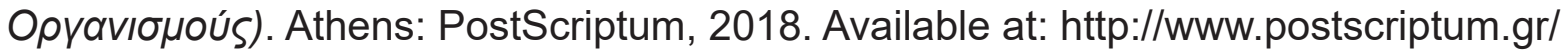
media/1995/booklet_synedriou_noe17.pdf. Date of Access: May 21, 2019.

ZORICH, Diane, Transitioning to a Digital World: Art History, Its Research Centers, and Digital Scholarship. Report to the Samuel H. Kress Foundation and the Roy Rosenzweig Center for History and New Media, George Mason University, 2012. Available at http://www.kressfoundation.org/research/transitioning_to_a_digital_ world/. Date of Access: May 21, 2019.

ZWEIG, Benjamin. Forgotten Genealogies: Brief Reflections on the History of Digital Art History. International Journal for Digital Art History, Munich, n. 1, p. 38-49, Oct. 2015. Available at: http://dah-journal.org/issue_01.html. Date of Access: May 21, 2019. 


\section{NOTES}

\section{AUTHOR DETAILS}

Alexandros Teneketzis: PhD. Postdoctoral researcher, University of the Aegean, Department of Cultural Technology and Communication, Mytilene, Greece.

\section{CORRESPONDENCE ADDRESS}

53-55 Elefteriou Venizelou str., 15341, Agia Paraskevi, Athens, Greece.

\section{ACKNOWLEDGEMENTS}

Many thanks to Angela Argentino for editing the English translation.

\section{FUNDING}

Not applicable.

\section{IMAGE USE AGREEMENT}

Not applicable.

\section{ETHICS COMMITTEE APPROVAL}

Not applicable.

\section{CONFLICT OF INTEREST}

There is no conflict of interest.

\section{LICENSE OF USE}

This article is licensed under the Creative Commons License CC-BY. With this license, you can share, adapt, create for any purpose, as long as the authorship is properly attributed.

\section{PUBLISHER}

Universidade Federal de Santa Catarina. Graduate Program in History. UFSC Journal Portal. The ideas expressed in this article are the sole responsibility of its author(s), and do not represent, necessarily, the opinion of the editors or the University.

\section{EDITORS}

Flávia Florentino Varella (Editor-in-chief)

Rodrigo Bragio Bonaldo

\section{HISTORY}

Received on: Oct. 16, 2019

Approved on: Mar. 27, 2020 